\title{
The Unfinished Agenda for Reproductive Health: Priorities for the Next 10 Years
}

\section{By Adrienne Germain and Jennifer Kidwell \\ Adrienne Germain is president and Jennifer \\ Kidwell is assistant communications officer, both at the International \\ Women's Health Coalition, New York.}

A decade ago, at the International Conference on Population and Development (ICPD) in Cairo, representatives from 179 countries, including the United States, agreed that reproductive rights are human rights. They also recognized that the most pressing international problems-poverty, hunger, disease, environmental degradation and political instability-can be solved only by securing women's sexual and reproductive health and rights.

Today, the ICPD agenda is vigorously alive. In 2004, all 179 original governments reaffirmed this watershed agreement. At the same time, nearly 100 current heads of state, along with three dozen Nobel Laureates, numerous business and religious leaders and many others, signed an unprecedented World Leaders' Statement in support of prioritizing the ICPD agenda. ${ }^{1}$ Since its presentation to the UN on October 13, 2004, the sponsors have collected even more signatures. Like the ICPD Programme of Action, this statement is a living document.

As we go forward from Cairo's 10th anniversary, it is vital not only to take stock of how far we have come, but to chart a course for where we are going. Given major global policy initiatives over the past 10 years, such as responses to the HIV/AIDS pandemic and the UN's Millennium Declaration and Millennium Development Goals (MDGs), what must happen in the next 10 years to secure sexual and reproductive health and rights for all? What should our priorities be?

In the last year or so, we have heard considerable naysaying regarding progress since Cairo. Granted, we have not made all the progress we hoped for, notably because of underfunding, destabilization caused by warfare and civil unrest, and the ravages of the HIV/AIDS epidemic. The glass, however, is half full, not half empty.

Where policies, budgets and programs reflect ICPD priorities, we see important progress. More women have access to contraceptives than ever before and more girls are in school. In the past decade, contraceptive prevalence among couples has increased from 55\% to $61 \% .^{2}$ Even in Africa, the region of the world where prevalence is lowest, contraceptive use among married women has risen from about $15 \%$ in the early 1990 s to $25 \%$ today, and in Asia, it has risen from 52\% to nearly 65\%. ${ }^{3}$ Between 1998 and 2001, Brazil reduced maternal deaths from roughly 34 to 29 per 100,000 hospital admissions, through the efforts of the government and nongovernmental organizations (NGOs). ${ }^{4}$ In Bangladesh, thanks to a coordinated government and civil society initiative, the proportion of women receiving antenatal care rose from 26\% in 1998 to $47 \%$ in 2002; dur- ing the same period, female life expectancy increased from 58 to 60 years, maternal mortality fell from 410 to 320 deaths per 100,000 live births, and the mortality rate for children younger than five dropped by $24 \% .{ }^{5}$ And, contrary to some assertions, the family planning program there, long a success story, has not faltered. ${ }^{6}$

Progress extends to the policies of UN agencies. Sexual and reproductive ill health accounts for an estimated onethird of the global burden of illness and early death borne by women of reproductive age, and 20\% for all people worldwide. ${ }^{7}$ In response, the World Health Assembly, in May 2004, adopted a strategy-based on the Cairo agreementsdesigned to accelerate progress toward reproductive health. The strategy, based on a human rights framework, focuses on the following five key action areas: strengthening health systems capacity; improving information for priority setting; mobilizing political will; creating supportive legislative and regulatory frameworks; and strengthening monitoring, evaluation and accountability. ${ }^{8}$

We can find positive examples from most countries, even those generally considered the toughest challenges. Take, for example, Nigeria. Soon after ICPD, a remarkable program-the Girls' Power Initiative (GPI)-was begun in southeast Nigeria. ${ }^{9}$ Ten years later, GPI is an internationally recognized organization running a comprehensive program designed to achieve gender equality in four Nigerian states. By offering information about health and rights, and by helping girls develop the skills to protect themselves and to challenge pervasive inequalities, the organization is changing attitudes and behavior. Program participants are getting an education instead of getting married young; they have resisted genital mutilation for themselves and their sisters; and they are changing the way their parents, siblings, peers and communities value young women.

In addition to the 1,500 girls directly involved in the program, GPI's message of empowerment now reaches another 25,000 female students through programs at 28 participating schools. Because of their success, GPI and colleague organizations across Nigeria are influencing national policies that affect girls' health and rights. The national government has adopted a national sex education curriculum and NGOs like GPI are helping implement it.

Finally, many in the sexual and reproductive health community are concerned that the MDGs do not include the central ICPD goal: universal access to sexual and reproductive health by 2015. Yet, more than any other UN conference in the 1990s, the Cairo meeting provided a foundation for the MDGs. The eight MDGs are coincident with 
the ICPD consensus, which recognized the need for a comprehensive approach to poverty reduction. Further, in their 2000 Millennium Summit Declaration, 189 heads of government set the MDGs in a broader context of human rights and democratic governance similar to that of the ICPD agreement. $^{10}$

Taken as a whole, these developments indicate that we are making strong progress on the sexual and reproductive health and rights agenda agreed upon in Cairo; that we have political support, as the countries most concernedand their heads of government-reaffirmed their commitment on the 10th anniversary of ICPD; and that the MDG framework encompasses and can promote the ICPD Programme of Action. Given the progress we have made-and the challenges ahead-we must continue to work toward full implementation of the goals agreed on in Cairo.

\section{FOUR PRIORITIES}

There are four top priorities to address in our unfinished reproductive health agenda: reproductive health and the MDGs, the feminization of the HIV/AIDS epidemic, comprehensive sex education and prevention of unsafe abortion.

\section{Reproductive Health and the MDGs}

Although the technical professionals who convened in 2001 to define targets and indicators for each MDG did not explicitly include the core ICPD goal, it is, nonetheless, implicit. There is increasing understanding that the MDGs cannot be achieved without substantial investment in the sexual and reproductive health and rights agenda set in Cairo. The final Millennium Project documents recognize, for example, the relevance of reproductive health and rights to the MDGs on gender, maternal health, child health, HIV/AIDS, hunger, poverty and environmental sustainability, ${ }^{11}$ as do the outcome documents of recent key UN meetings like the Commission on the Status of Women and the Commission on Population and Development.

Women's health advocates must intensify their efforts to foster alliances across sectors to ensure that sexual and reproductive health and rights figure prominently in both global and national strategies to achieve the MDGs. For example, preparations for the summit-level review of progress toward MDG achievement, scheduled for September 2005, provide several ways to promote understanding of the reciprocal relationship between reproductive health and the MDGs. In particular, the family planning and reproductive health communities should emphasize that combating HIV/AIDS (Goal 6) requires universal access to reproductive health services, which leads to our second priority for the reproductive health agenda.

\section{Feminization of the HIV/AIDS Epidemic}

The increasingly widespread feminization of the HIV/AIDS pandemic is clear and frequently acknowledged. For example, just prior to World AIDS Day 2004, which focused on women, girls and HIV/AIDS, UNAIDS announced that women's rates of infection were increasing in every region of the world. ${ }^{12}$ Even in Brazil and Thailand, whose epidemics have stabilized in the past several years, evidence is mounting that wives and primary female partners, as well as adolescent girls, are at increasing risk. ${ }^{13}$

HIV/AIDS policymakers have yet to invest in concrete action plans and policies to prevent infection in the majority of girls and women, although there is an action plan readily available: the ICPD Programme of Action. The realities of girls' and women's lives that put them at high risk of infection are the same realities that ICPD addressed, including, for example, marriage of adolescent girls to older, sexually experienced men; husbands who engage in extramarital sex; violence and sexual coercion inside and outside marriage; unequal access to education, productive assets and employment; and taboos against giving girls factual information about sexuality and reproduction before and after marriage. Because of all these factors, the "ABC"

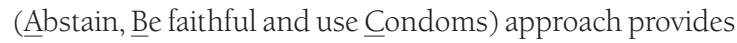
little protection for the most vulnerable girls and women.

Ten years after the ICPD paradigm shift in population policy, we need another paradigm shift to bring HIV/AIDS policies closer to women's realities. An "ABC Plus" approach, such as the one advocated by the United Nations Secretary General's Task Force on Women, Girls and HIV/AIDS in Southern Africa, as well as the Global Coalition on Women and AIDS, ${ }^{14}$ should focus on the ICPD principles of educating and empowering women, and securing their health and rights.

We will best reach women of all ages by investing HIV/ AIDS resources in strengthening and expanding access to health services and programs they use-namely, reproductive health programs.

Unlike HIV-specific clinics and education programs, which are too often stigmatized and inaccessible (especially for rural women), reproductive health services have established community support and a head start of several decades on core staff and management capacities. Significantly increased resources are needed, both to reach more girls and women, and to add HIV/AIDS-related capabilities. For example, the World Health Organization (WHO) estimates that there are approximately 600,000 doctors, nurses and trained midwives in all Sub-Saharan African countries combined. Even by conservative estimates, at least three times that number are needed to meet the reproductive health needs of African women. ${ }^{15}$ If we invest wisely, especially at the primary and secondary levels, we will reap benefits beyond women's health, namely stronger public health systems that can provide HIV/AIDS interventions and health services for all.

Prevention of HIV/AIDS in girls and women also requires development and provision of female-initiated and -controlled HIV-prevention methods. We must make it a priority to ensure that all reproductive health services offer and promote both male and female condoms, and that health workers are trained to provide them. The efficacy of the female condom has been well established, and numerous successes with its introduction have been docu- 
mented. For example, intensive social marketing campaigns in South Africa, Brazil, Ghana and Zimbabwe have generated demand. ${ }^{16}$ However, we need to undertake further research on acceptability, design, benefits, and ways to promote and distribute this method.

In addition, funding is urgently needed to develop microbicides-topical substances that women can apply in the vaginal or anal area to reduce transmission of HIV and other STIs-and bring them to market. With sufficient support, these substances could be available as soon as 3-4 years from now. ${ }^{17}$ U.S. government funding of microbicides research and development has increased from \$35 million in FY 2000 to $\$ 89$ million in FY 2004. ${ }^{18}$ Other donors, including the governments of Denmark, Ireland, Norway and the United Kingdom, and foundations like Ford, Gates and Rockefeller, are making important investments. However, much more funding is needed; a 2001 report by The Rockefeller Foundation found that roughly $\$ 775$ million would need to be invested over five years to make development of a safe and effective product probable by $2010 .{ }^{19}$

Finally, policymakers and implementers must complement investments in reproductive health services with health education and outreach to provide information on the spectrum of sexual and reproductive health issues (including HIV/AIDS), and to inform husbands and partners about, and encourage their respect for, sexual and reproductive rights. This leads to the third priority in the unfinished reproductive health agenda.

\section{Rights-Based Comprehensive Sex Education}

Today's more than two billion young children and adolescents, the majority of whom live in poor countries, will largely determine the growth rate and size of the world's population, and many of them are also extremely vulnerable to HIV infection. Young women now account for $62 \%$ of persons aged 15-24 who are living with HIV/AIDS worldwide. In Sub-Saharan Africa, $75 \%$ of infected young people are female. ${ }^{20}$ If these young people do not receive adequate reproductive and sexual health services and education now, if girls do not have equal access to schools, and if both boys and girls foresee a future of unemployment and poverty, both demographic momentum and the HIV/AIDS pandemic will surely continue into future generations.

Recent research by U.S. congressman Henry Waxman found that many abstinence-only sex education programs in the United States currently use curricula with dangerous misinformation about HIV/AIDS, pregnancy and other crucial health issues. ${ }^{21}$ The U.S. government is directing more and more funds toward abstinence-only programs: domestically, a total of $\$ 170$ million (more than twice the amount spent in 2001, but $\$ 100$ million less than requested by the Bush administration); and internationally, one-third of the prevention funds in the President's Emergency Plan for AIDS Relief. In contexts where rates of HIV infection, unintended pregnancy and child marriage are high, adolescents' ability to make informed decisions about their sexual lives is a life-and-death matter.
Effective programs for comprehensive sex education include abstinence as one important option; provide factual information; give social support; and help young people build skills to establish equality within their relationships, respect the right to consent in the context of both sex and marriage, and end violence and sexual coercion. Such programs should provide girls with safe spaces, free from harassment and discrimination; alternatives to early marriage; and activities to help build their self-esteem and confidence. Current adolescent programs typically fall far short of this standard, but the GPI program in Nigeria and others like it show the way. ${ }^{22}$ In Cross River, one state where GPI works and where HIV prevalence has reached $12 \%$ among sexually active individuals, ${ }^{23}$ health providers say that program participants exhibit knowledge and initiative when it comes to protecting their sexual and reproductive health. ${ }^{24}$

\section{Prevention of Unsafe Abortion}

The ICPD Programme of Action recognized unsafe abortion as a major public health concern, and the five-year review of progress reaffirmed the need to address this problem. An important means of reducing unsafe abortion is to ensure accessible, high-quality family planning services. In addition, governments agreed at ICPD +5 that, where legal, abortion must be safe. ${ }^{25}$ Nevertheless, many women eligible under the laws of their countries still do not have access to safe services. Every year, 19 million unsafe abortions take place around the world. The complications resulting from these procedures lead to at least 68,000 deaths, 99\% of them in developing countries. ${ }^{26}$

Internationally, a significant number of countries have taken action and have amended laws and regulations. For example, in more than 15 countries, NGOs and parliamentarians are working to raise public awareness that unsafe abortion maims and kills, to reduce constraints that result in high rates of mortality and morbidity from unsafe abortion, and to ensure that women suffering from complications of unsafe abortion are treated for their injuries, not criminalized. Additionally, governments, NGOs and health professionals are using WHO's technical and policy guidance to train health care providers, inform program managers and policymakers and educate the public. ${ }^{27}$

\section{CONCLUSION}

These four priorities-reproductive health and the MDGs, the feminization of the HIV/AIDS epidemic, sex education and prevention of unsafe abortion-pose substantial challenges. Keeping the Cairo promise, especially to women and the largest-ever generation of young people, requires work with policymakers-and the demographers, epidemiologists and economists who advise them-to think anew about the underlying dynamics driving population growth, persistent and widespread reproductive health problems, violations of sexual and reproductive rights and the HIV/AIDS pandemic. It requires engaging currently separate communities in partnership: HIV/AIDS activists, women's health advocates, youth leaders, human rights ac- 
tivists and the reproductive health and population field. It also requires leadership, time and resources.

Working together, we can build a diverse and powerful coalition that mobilizes more resources for sexual and reproductive health services, rights-based youth education programs and HIV/AIDS prevention approaches that address the realities of girls' and women's lives. At the same time, we can work together to develop stronger evidence concerning the effectiveness of all these interventions.

In March 2005, governments convened in New York for the 10-year review of implementation of the Platform for Action agreed on by the 1995 Fourth World Conference on Women in Beijing. In Beijing, governments reaffirmed and moved beyond the Cairo agreement to operationalize the sexual and reproductive rights it defined. With Beijing, as with ICPD, we can see both inspiring successes and formidable challenges as we look back over the 10 years since the conference. This year, governments unanimously recommitted themselves to implementing both the Beijing Declaration and the Platform for Action, and also recognized the critical connection between these documents and the MDGs. As we move forward from the Beijing review, through the Millennium Summit in September and beyond, we must ensure that these four priorities on the unfinished reproductive health agenda will be addressed.

Building alliances around our priorities will be challenging, at least as challenging as the work that generated the ICPD paradigm shift in population policy. But we can take advantage of fundamental political arithmetic; the bigger, the broader, the more organized a constituency, the more effective it will be. In politics, two plus two can equal five. The payoff will be huge-saving millions of lives, both now and in generations to come.

\section{REFERENCES}

1. Afwerki I et al., World leaders statement in support of ICPD, Jan. 19, 2005, <http://www.icpdleadersstatement.net/documents/statement.htm>, accessed Dec. 22, 2004.

2. United Nations Population Fund (UNFPA), State of World Population 2004-The Cairo Consensus at 10: Population, Reproductive Health and the Global Effort to End Poverty, New York: UNFPA, 2004

3. Ibid.; and United Nations Population Division, World contraceptive use 2001, wall chart, New York: UN, 2001.

4. Brazil Ministry of Health, Principles and directives for integrated attention to women's health, 2004-7, Brasilia, Brazil: June 2003.

5. Jahan R, Restructuring the health system: experiences of advocates for gender equity in Bangladesh, Reproductive Health Matters, 2003, No. 21, pp. 183-191.

6. National Institute for Population Research and Training, Mitra and Associates and Macro International, Bangladesh Demographic and Health Survey, 2004, Preliminary Report, Calverton, MD: Macro International, 2004 , p. 8

7. The Alan Guttmacher Institute (AGI) and UNFPA, Adding It Up: The Benefits of Investing in Sexual and Reproductive Health Care, New York: AGI, 2003.

8. World Health Organization (WHO), Reproductive Health Strategy to Accelerate Progress Towards the Attainment of International Development
Goals and Targets, Geneva: WHO, 2004.

9. Madunagu B and Schreck L, Girl power: asserting sexual rights in Nigeria, Open Society News, June 2001, pp. 8-9.

10. United Nations General Assembly, United Nations millennium declaration, Sept. 18, 2000, <http://www.un.org/millennium/declaration/ ares552e.pdf>, accessed Apr. 5, 2005.

11. United Nations Millennium Project, Investing in Development: A Practical Plan to Achieve the Millennium Development Goals, New York: United Nations Development Programme, 2005.

12. The Joint United Nations Programme on HIV/AIDS (UNAIDS), AIDS Epidemic Update: December 2004, Geneva: UNAIDS, 2004.

13. Teixeira PR, Sexual and reproductive health and the HIV/AIDS epidemic in Brazil, presentation at the Sex and the Hemisphere Symposium of the International Planned Parenthood Federation, Western Hemisphere Region, New York, Oct. 20, 2004; and UNAIDS, 2004 Report on the Global AIDS Epidemic, Geneva: UNAIDS, 2004.

14. UNAIDS, ABC Plus: preventing HIV infection amongst women and girls in Southern Africa, fact sheet, Geneva: UNAIDS, 2004.

15. Germain A and Chen L, personal correspondence, Dec. 8, 2004.

16. Hoffman $S$ et al., The future of the female condom, International Family Planning Perspectives, 2004, 30(3):139-145.

17. Henry J. Kaiser Family Foundation, Female-controlled microbicide to prevent HIV infection could be available in three to four years, Piot says, <http://www.kaisernetwork.org/daily_reports/rep_index.cfm?hint= 4\&DR_ID=29396>, accessed Apr. 15, 2005.

18. Global Campaign for Microbicides and Alliance for Microbicide Development, Microbicide research and development: federal expenditures, FY-1997 to FY-2004 (US\$), Washington, DC: Global Campaign for Microbicides, 2004

19. Pharmaco-Economics Working Group of The Rockefeller Foundation Microbicides Initiative, The Economics of Microbicide Development: A Case for Investment, New York: The Rockefeller Foundation, 2001.

20. UNAIDS, 2004, op. cit. (see reference 12).

21. U.S. House of Representatives Committee on Government Reform, Minority Staff, Special Investigations Division, The Content of Federally Funded Abstinence-Only Education Programs, report prepared for U.S. Rep. Henry A. Waxman, 2004, <http://reform.democrats.house.gov/ story.asp?id=734>, accessed Dec. 22, 2004.

22. Irvin A, Taking Steps of Courage: Teaching Adolescents About Sexuality and Gender in Nigeria and Cameroun, New York: International Women's Health Coalition, 2000.

23. Bryant E, Lessons for living, Ford Foundation Report, Spring 2004 pp. 8-15.

24. Girls' Power Initiative (GPI), GPI at 10: A Decade of Roses, Thorns, and Change, Calabar, Nigeria: GPI, 2004.

25. United Nations, Key Actions for the Further Implementation of the Programme of Action of the International Conference on Population and Development, adopted by the 21st special session of the General Assembly, New York: United Nations, 1999.

26. Division of Reproductive Health, WHO, Unsafe Abortion: Global and Regional Estimates of Incidence of Unsafe Abortion and Associated Mortality, fourth ed., Geneva: WHO, 2004.

27. WHO, Safe Abortion: Technical and Policy Guidance for Health Systems, Geneva: WHO, 2003.

\section{Acknowledgments}

The authors would like to thank Sue Hornik for her work on the early stages of this draft.

Author contact: jkidwell@iwhc.org 